\title{
FATIGUE RELIABILITY ASSESSMENT OF ORTHOTROPIC STEEL BRIDGE DECKS BASED ON PROBABILISTIC MULTI-SCALE FINITE ELEMENT ANALYSIS
}

\author{
Tong Guo ${ }^{1,2,}$, Zhong-xiang Liu $^{2}$ and Jin-song Zhu ${ }^{3}$ \\ ${ }^{1}$ Key Laboratory of Concrete and Prestressed Concrete Structures of the Ministry of Education, Southeast \\ University, Nanjing, China \\ ${ }^{2}$ School of Civil Engineering, Southeast University, Nanjing, China \\ ${ }^{3}$ School of Civil Engineering, Tianjin University, Tianjin, China. \\ *(Corresponding author: E-mail: guotong@seu.edu.cn)
}

\begin{abstract}
The orthotropic steel deck (OSD) has been utilized successfully for thousands of bridges worldwide; however, fatigue cracking of the OSD has been observed frequently due to the complicated welded details combined with stresses that can be difficult to quantify, and the uncertainties in fatigue damage accumulation. In this paper, a fatigue reliability assessment method is proposed based on a comprehensive vehicle load model and probabilistic multi-scale finite element (FE) analysis. The vehicle load model, obtained from statistical data of toll stations, consists of probability distribution functions regarding the number of axles, axle weights, and transversal positions of vehicles, etc. The multi-scale finite element model not only captures the main features of the entire bridge but also gives an accurate description on local stress responses of the OSD in a relatively efficient way. Based on the probabilistic FE analysis combined with the developed vehicle load model, the fatigue reliabilities of the OSD could be obtained. Application of the proposed method is made in the fatigue reliability assessment of the OSD of the Runyang Cable-stayed Bridge for demonstration.
\end{abstract}

Keywords: Fatigue reliability; Orthotropic steel deck; Vehicle load; Multi-scale; Finite element analysis

DOI: $10.18057 / \mathrm{IJASC} .2015 .11 .3 .7$

\section{INTRODUCTION}

The orthotropic steel deck (OSD) has been utilized successfully for thousands of bridges worldwide due to its notable advantages [1], i.e., increased rigidity, material savings, low maintenance, suitability for standardization and prefabrication, etc. However, fatigue cracking of the OSD is frequently observed in practice [2-5], resulting in considerable maintenance or rehabilitation costs. During the past decades, design specifications and approaches to predict the remaining fatigue life of the OSD have been developed and applied actively [6-10]. However, the challenge for extending the fatigue life of the OSD still exists, resulting from the complicated welded details in which stresses can be difficult to quantify. Besides, with the increase of span lengths, bridges are becoming more flexible, which makes them more vulnerable to the vehicle loads, wind-induced vibration and/or fluctuations of ambient temperatures [11]. Therefore, the accurate prediction of fatigue life of the OSD requires that all influencing factors should be taken into account, which includes not only the configuration of fatigue details and vehicle loads but also the global structural behavior and/or environmental effect, etc.

In fatigue analyses, one important step is to obtain the fatigue stress spectra, and in general there are two types of approaches, namely the model-based approaches and monitoring-based approaches. The traditional way of obtaining the fatigue stress spectra on bridges is based upon the stress analysis with a traffic load model and a structural model [12-13]. Therefore, the accuracy of model-based approaches depends upon the rationality of traffic load models as well as the structural models. The monitoring-based approaches, however, provide authentic fatigue stress spectra. Especially, the recent development of structural health monitoring (SHM) systems enables long-term measurements on structural responses of bridges subjected to various loads and their 
combined action [14-18]. However, the long-term SHM is often costly and not all concerned details could be covered due to limited budget.

In addition, fatigue analyses also abound with uncertainties, coming from external loads, material properties, corrosion actions and/or the measured data themselves, etc [19-23]. In order to study the fatigue reliability of the OSD under the combined action of vehicle loads and environmental factors, a probabilistic FE approach is proposed in this paper, which consists of a comprehensive vehicle model, obtained from statistical data of toll stations, and a multi-scale FE model that simulates the global responses of the whole bridge as well as the local stresses of fatigue-prone details in the OSD. Combined with a certain ambient temperature model, the coupling effect due to ambient temperature and vehicle loads is taken into account.

\section{VEHICLE LOAD MODELS}

According to the records from toll stations of the Runyang Bridge (consisting of a cable-stayed bridge and a suspension bridge), there were a total of 371,167 vehicles passing through the bridge during July 28, 2011 to August 31, 2011. Information including the types of vehicles, number of vehicles in each type, number of axles, and axle weights, etc., is obtained and analyzed. Using the video camera, the transversal positions (i.e., outer lane, middle lane or inner lane) are also identified.

Table 1. Probabilistic Properties of Axle Weights (dimensions in kN)

\begin{tabular}{|c|c|c|c|c|c|}
\hline $\begin{array}{c}\text { Vehicle } \\
\text { type }\end{array}$ & Graphic illustration & $\begin{array}{c}\text { Variable } \\
\text { designation }\end{array}$ & $\begin{array}{c}\text { Distribution } \\
\text { type }\end{array}$ & $\begin{array}{l}\text { Mean } \\
\text { value }\end{array}$ & $\begin{array}{l}\text { Standard } \\
\text { deviation }\end{array}$ \\
\hline \multirow[b]{2}{*}{1} & $A W_{11}$ & $A W_{11}$ & Lognormal & 10.54 & 3.12 \\
\hline & (๑) $A P_{11} \stackrel{\circ}{\circ}$ & $A W_{12}$ & Lognormal & 8.55 & 3.27 \\
\hline \multirow{2}{*}{2} & $A W_{21} \quad A W_{22} A W_{23}$ & $A W_{21}$ & Normal & 48.29 & 14.22 \\
\hline & $\begin{array}{lll}\text { (c) } & A P_{21} & A P_{22} \\
+ & +\end{array}$ & $A W_{22}=A W_{23}$ & Normal & 78.54 & 36.48 \\
\hline \multirow{3}{*}{3} & $A W_{31} A W_{32} \quad A W_{33}$ & $A W_{31}$ & Normal & 38.16 & 10.39 \\
\hline & (०) (०) & $A W_{32}$ & Normal & 35.66 & 12.87 \\
\hline & $+A P_{31}+A P_{32}+$ & $A W_{33}$ & Lognormal & 115.10 & 65.54 \\
\hline \multirow{4}{*}{4} & $A U$ & $A W_{41}$ & Normal & 46.26 & 10.03 \\
\hline & & $A W_{42}$ & Lognormal & 52.40 & 15.50 \\
\hline & $t_{43}$ & \multirow{2}{*}{$A W_{43}=A W_{44}$} & Normal (0.18) & 33.83 & 5.70 \\
\hline & & & Normal $(0.82)$ & 82.30 & 29.84 \\
\hline \multirow{7}{*}{5} & & $A W_{51}$ & Lognormal & 48.46 & 6.33 \\
\hline & & \multirow{3}{*}{$A W_{52}$} & Normal (0.23) & 43.56 & 3.29 \\
\hline & $A W_{51} \quad A W_{52} \quad A W_{53} A W_{54} A W_{55}$ & & Normal (0.37) & 74.01 & 24.03 \\
\hline & (०) & & Normal $(0.4)$ & 132.12 & 18.12 \\
\hline & . ${ }^{A P_{51}}$. & \multirow{3}{*}{$A W_{53}=A W_{54}=A W_{55}$} & Normal (0.27) & 22.96 & 1.71 \\
\hline & & & Normal $(0.30)$ & 52.23 & 13.92 \\
\hline & & & Normal $(0.43)$ & 83.35 & 9.51 \\
\hline \multirow{6}{*}{6} & \multirow{6}{*}{ 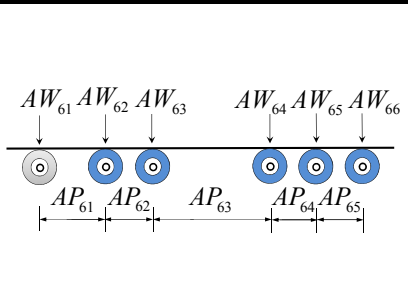 } & $A W_{61}$ & Lognormal & 53.86 & 5.95 \\
\hline & & \multirow{3}{*}{$A W_{62}=A W_{63}$} & Normal (0.13) & 35.35 & 4.79 \\
\hline & & & Normal (0.87) & 82.17 & 15.62 \\
\hline & & & Normal (0.07) & 22.68 & 3.20 \\
\hline & & \multirow[t]{2}{*}{$A W_{64}=A W_{65}=A W_{66}$} & Normal (0.16) & 38.11 & 13.95 \\
\hline & & & Normal (0.77) & 80.94 & 13.11 \\
\hline
\end{tabular}


As summarized in Table 1, there are mainly six types of vehicles crossing the bridge, and the axle weights of most types of vehicles can be described by a single-peak probability density function (PDF), as shown in Figure 1. However, for the last three types, multi-peaks exist in the PDFs, and therefore, a weighted sum of PDFs are used to describe such distributions. For example, the normal PDF is a non-skewed one and suitable for negative as well as positive variables; while the lognormal PDF is suitable for skewed distribution but only suitable for positive variables. For the multi-peaks distribution, the optimal number of PDFs, weights, and parameters of these PDFs can be determined through existing literature [24]. In this study, normal, lognormal PDFs and their combination are used. It is observed from Table 1 that the vehicle type 1 with two axles takes a large portion of the traffic volume (i.e., 76.7 percent), followed by the vehicle type 6 with six axles (taking about 16.94 percent), indicating that there is a considerable portion of heavy trucks in the total traffic volume. However, the portion of vehicle type 2 with three axles is very small, i.e., 0.65 percent, and vehicle types 3, 4 and 5 are all within $5 \%$ of the traffic volume.

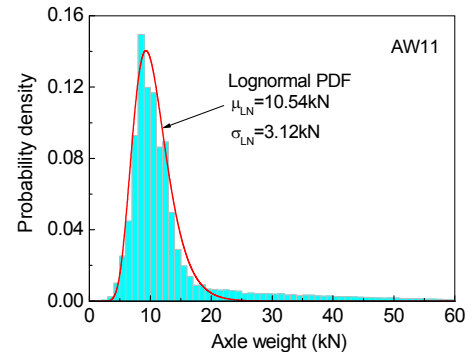

(a) $A W_{11}$

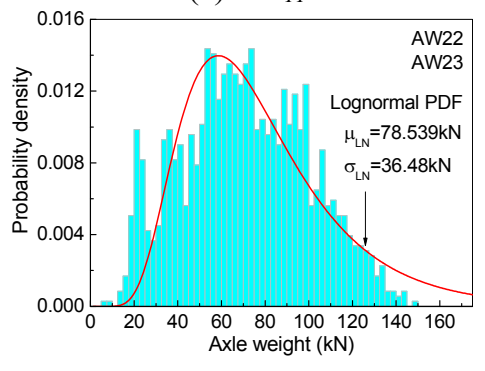

(d) $A W_{22}=A W_{23}$

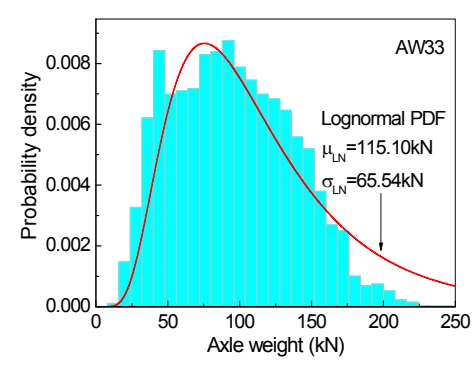

(g) $A W_{33}$

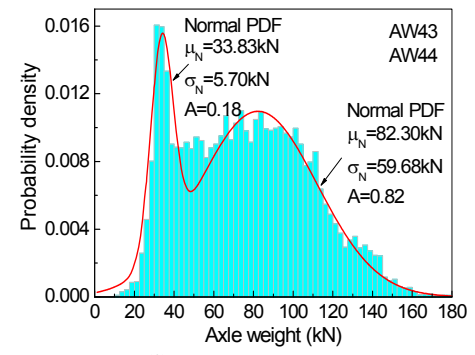

(j) $A W_{43}=A W_{44}$

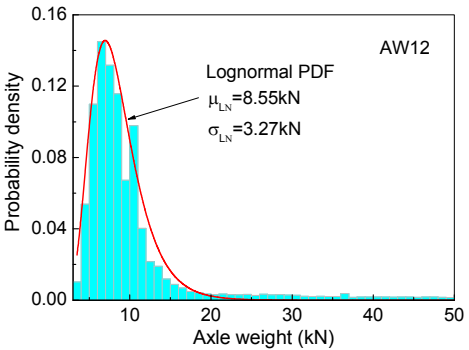

(b) $A W_{12}$

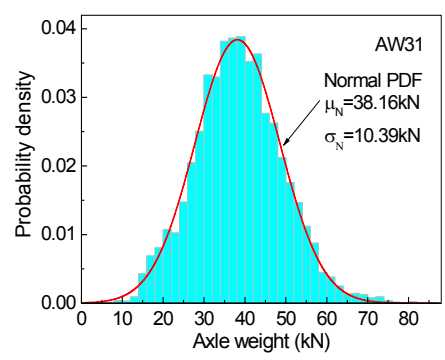

(e) $A W_{31}$

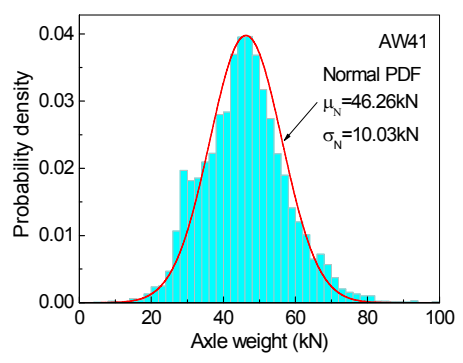

(h) $A W_{41}$

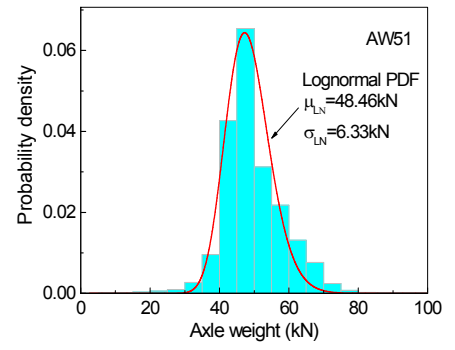

(k) $A W_{51}$

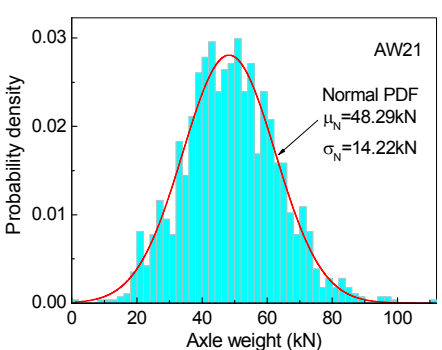

(c) $A W_{21}$

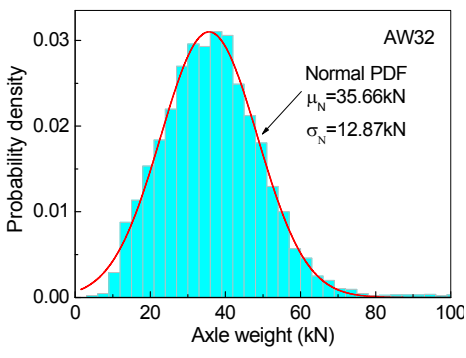

(f) $A W_{32}$

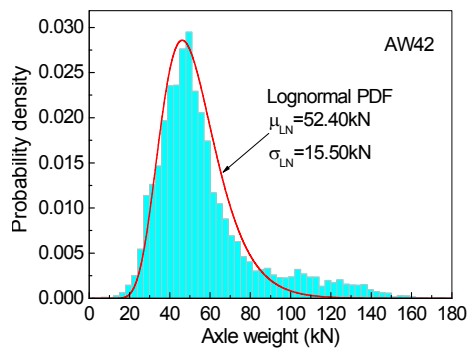

(i) $A W_{42}$

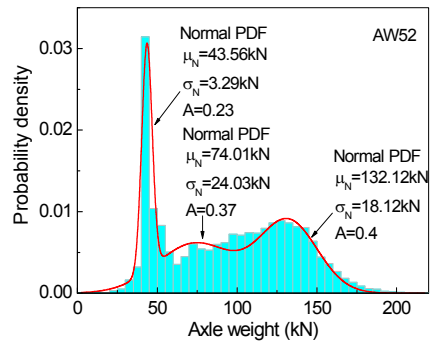

(1) $A W_{52}$ 


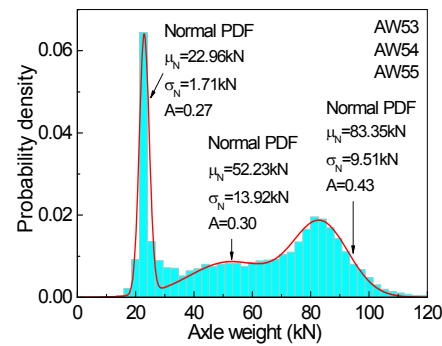

(m) $A W_{53}=A W_{54}=A W_{55}$

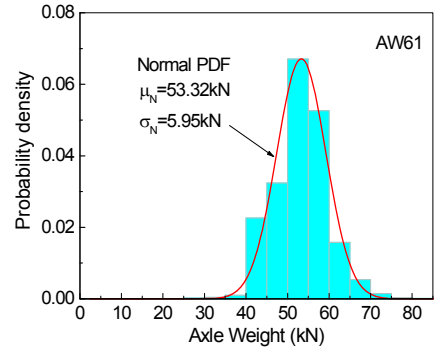

(n) $A W_{61}$

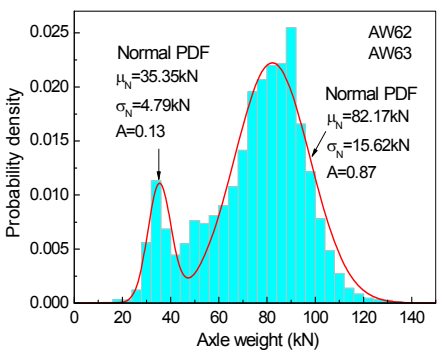

(o) $A W_{62}=A W_{63}$

Figure 1. PDFs of Axle Weights

In addition, 36.65 percent and 42.03 percent vehicles ran in the middle lane and inner lane (i.e., the fast lane), respectively; whereas 21.32 percent vehicles ran in the outer lane (i.e., the slow lane). For the vehicle type 1 with light weight, most of them (i.e., 41.23 percent) were in the fast lane, and only 9.7 percent were in the slow lane. However, for the vehicle type 6 with heavy weight, their lane occupation was just opposite to that of vehicle type 1 . Most heavy trucks were in the middle lane and the slow lane while only a small portion of them were in the fast lane.

Table 2. Constitution of Vehicles

\begin{tabular}{ccccc}
\hline \multirow{2}{*}{ Vehicle type } & \multirow{2}{*}{ Percentage in traffic volume (\%) } & \multicolumn{3}{c}{ Percentage in each lane (\%) } \\
& & Outer lane & Middle lane & Inner lane \\
\hline 1 & 76.66 & 9.70 & 25.74 & 41.23 \\
2 & 0.65 & 0.36 & 0.26 & 0.03 \\
3 & 1.57 & 0.60 & 0.87 & 0.10 \\
4 & 1.64 & 0.92 & 0.67 & 0.04 \\
5 & 2.54 & 1.31 & 1.17 & 0.06 \\
6 & 16.94 & 8.43 & 7.94 & 0.57 \\
\hline
\end{tabular}

\section{MULTI-SCALE FE MODELING OF RUNYANG CABLE-STAYED BRIDGE}

\subsection{Bridge Description}

In this paper, the proposed method is demonstrated through the fatigue reliability assessment of the Runyang Cable-stayed Bridge (RCB). The RCB, connecting Yangzhou and Zhenjiang, has a total length of $756.8 \mathrm{~m}$, consisting of a main span of $406 \mathrm{~m}$ and two side spans of $175.4 \mathrm{~m}$, respectively. The two vase-shaped concrete towers are $146.9 \mathrm{~m}$ high, and each of them has two reinforced concrete legs and three prestressed concrete cross-beams, supporting the bridge girder through stay cables. The girder is an aerodynamically shaped closed steel box one with a width of $37.4 \mathrm{~m}$ and a height of $3.0 \mathrm{~m}$, as shown in Figure 2(a), carrying two carriageways and each has three lanes. Two steel trusses, as shown in Figure 2(b), are placed longitudinally along the girder, so as to provide additional bending stiffness.

\subsection{Finite Element Modeling}

A multi-scale FE model of the RCB is developed using the FE program ANSYS, as shown in Figure 3, As demonstrated in previous study integrating multi-scale FE modeling [17], a tradeoff should be made elaborately between accuracy and computational efficiency. In this study, the 
towers are modeled using the 3D iso-parametric beam elements (i.e., the Beam 4 element in ANSYS) having six DOFs at each node.

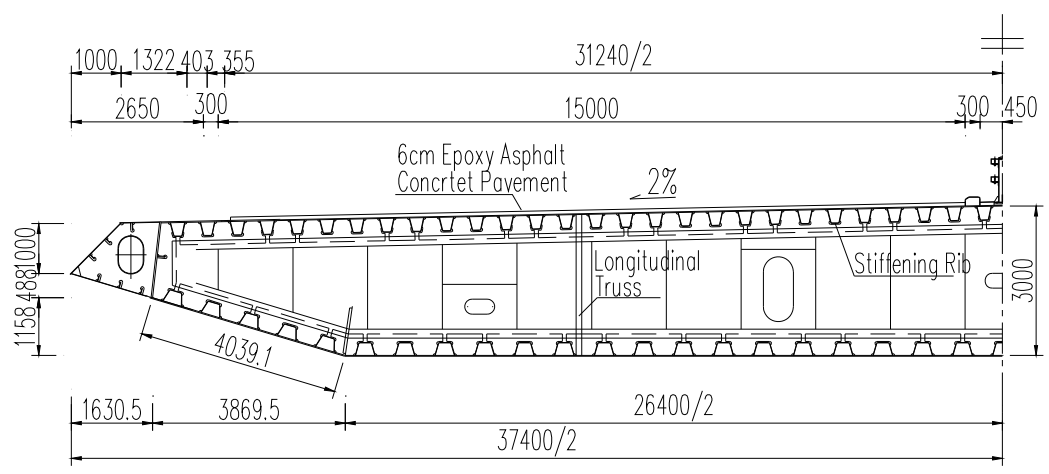

(a) Cross-section of Steel Box-girder

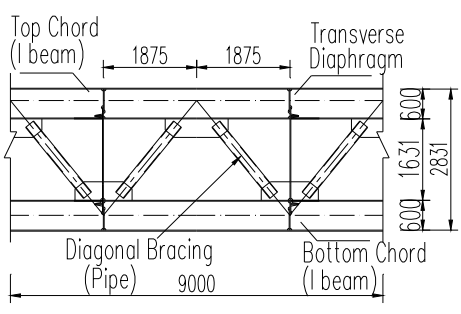

(b) Longitudinal Truss

Figure 2. Box-girder of the RCB and Its Longitudinal Truss (dimension unit in $\mathrm{mm}$ )

The stayed-cables are modeled using the 3D linear elastic link elements (i.e., the Link 10 element) with three degrees of freedom (DOF) for each node. This link element is defined to bear tension only. The cable stresses in the equilibrium configuration are input in terms of initial strains. The material properties and real constants (i.e., areas of cross-section, moments of inertia, etc.) are strictly calculated and assigned to the corresponding elements. The box girders are modeled using shell elements (i.e., the shell 63 element). To reduce the number of elements, the orthotropic decks and bottom plates of the girder are modeled respectively using a layer of plates without U-ribs, and these plates are assigned with orthotropic material properties. The element dimension of such deck plates is $0.3 \mathrm{~m}$ (transversal) $\times 1.5 \mathrm{~m}$ (longitudinal) for most parts. However, to have a precise observation on the deck details, the decks near the mid-span are refined twice. The first refinement is conducted for decks with a distance no larger than $50.5 \mathrm{~m}$ to the mid-span, and U-ribs are modeled with an element dimension of $0.3 \mathrm{~m}$ (transversal) $\times 0.35 \mathrm{~m}$ (longitudinal). The second refinement is conducted for decks with a distance within $1.75 \mathrm{~m}$ to the mid-span, and the element dimension is $0.033 \mathrm{~m}$ (transversal) $\times 0.039 \mathrm{~m}$ (longitudinal). In addition, the layered element (i.e., Shell 181 element) is used for the top plate, which simulates the $14 \mathrm{~mm}$ thick steel plates as well as the $60 \mathrm{~mm}$ thick epoxy asphalt concrete pavements. Different elastic moduli and thicknesses are assigned to the elements. The concrete and steel blocks, placed inside the box-girders at two side spans to adjust the configuration of the bridge, are modeled using the Mass 21 element. To simulate the influence of ambient temperature on the structural responses, temperatures are applied as a form of load in the FE analysis. The coefficients of the thermal expansion of concrete and steel are set as $1.0 \times 10^{-5} /{ }^{0} \mathrm{C}$ and $1.2 \times 10^{-5} /{ }^{0} \mathrm{C}$ respectively. In addition, past investigation revealed that temperature fluctuation may soften or stiffen the epoxy asphalt concrete pavements, as shown in Table 3, and thus influences the stresses of the decks under a moving vehicle [11]. Therefore, in this study, the elastic modulus of the pavements (i.e., the top layer of the Shell 181 element) is updated with different temperature value.

Table 3. Changes in the Elastic Modulus of Pavements with Different Temperatures [11]

\begin{tabular}{lllllllllllllll}
\hline Temperature $\left({ }^{\circ} \mathrm{C}\right)$ & 60 & 55 & 50 & 45 & 40 & 35 & 30 & 25 & 20 & 15 & 10 & 5 & 0 & -5 \\
\hline Elastic modulus $(\mathrm{MPa})$ & 300 & 337 & 374 & 411 & 448 & 485 & 522 & 559 & 596 & 633 & 670 & 707 & 744 & 781 \\
\hline
\end{tabular}

The displacements of the girders at two ends are coupled with those of tower cross-beams, except that the longitudinal displacement is free. This is to simulate the connection of the slide bearing between girders and towers. In total, there are 584,784 shell elements, 3,752 beam elements, 104 link elements, and 3,174 mass elements in the FE model. 


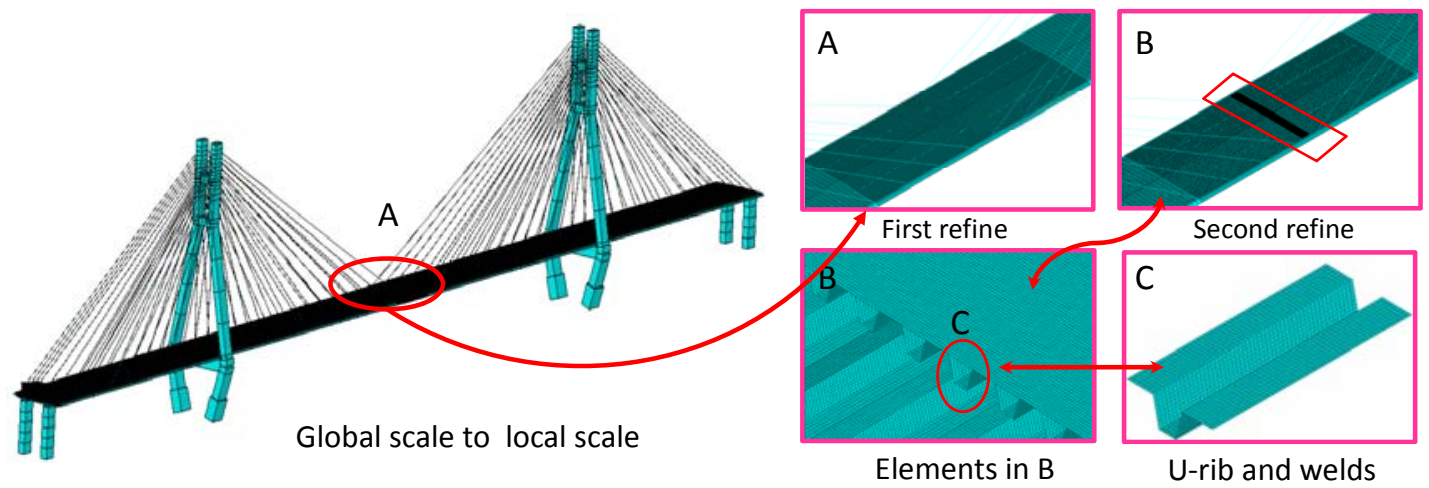

Figure 3. Multi-scale FE Model of the RCB

\subsection{Validation of FE Model}

Field measured data in the controlled load tests of the RCB are used to calibrate the above FE model, and two typical load cases, as shown in Table 4 are selected for illustration purpose. Dump trucks, as shown in Table 5, were used in the field tests, and each truck had a weight of $300 \mathrm{kN}$. Strain gauges installed at the mid-span cross-section of the girder were used to measure the normal stresses during the tests, as shown in Figure 4. Note that the prefixes "T" and " $U$ " in Figure 4 denote that the gauges are on top plates and U-ribs, respectively.

Table 4. Description of Load Cases

\begin{tabular}{ll}
\hline Load test & Truck positions \\
Case 1 & $\begin{array}{c}\text { Eight trucks, symmetrically loaded at the mid-span } \\
\text { in } 4 \text { lines and } 2 \text { rows, }\end{array}$ \\
Case 2 & All the trucks in Case 1 move $1.75 \mathrm{~m}$ forward
\end{tabular}

Table 5. Trucks Used in the Controlled Load Tests

\begin{tabular}{cccccc}
\hline \multirow{2}{*}{ Load case } & \multirow{2}{*}{ Wheel loads $(\mathrm{kN})$} & \multicolumn{2}{c}{ Wheel prints $(\mathrm{mm})$} & \multicolumn{2}{c}{ Distance between $(\mathrm{mm})$} \\
& & Width & Length & Wheels & Axles \\
\hline Single tyre (front axle) & 30 & 299.9 & 375 & 1700 & 3500 \\
Double tyre (rear axle) & 60 & 598.8 & 375 & 2000 & 1300 \\
\hline
\end{tabular}

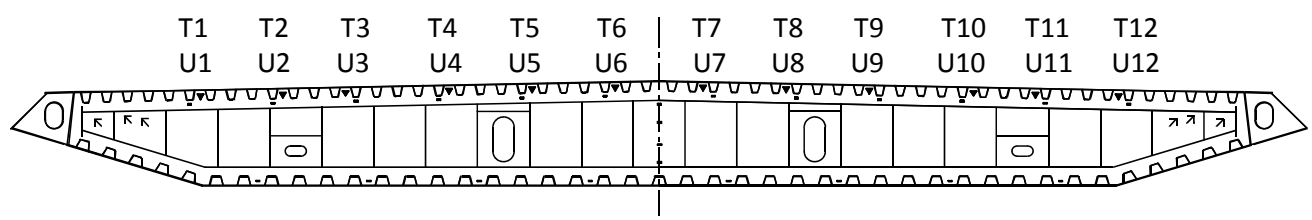

Figure 4. Layout of Strain Gauges at Mid-span Cross-section of the Girder

According to the vehicle parameters in the controlled load tests such as axle weight, axle spacing, etc., tyre loads are applied to selected deck elements and static elastic analyses are performed. Figure 5 illustrates the comparison between the calculated and measured stresses, where good 
agreement is observed, showing the effectiveness of the FE model. It is worth noting that the difference in the stresses of top plates between two cases are in general not large, and similar stress distributions on the cross-section of girder between two cases are observed; however, significant differences exist in the stresses of U-ribs between the two cases, both in stress magnitudes and distribution patterns, which may be attributed by the longitudinal trusses.

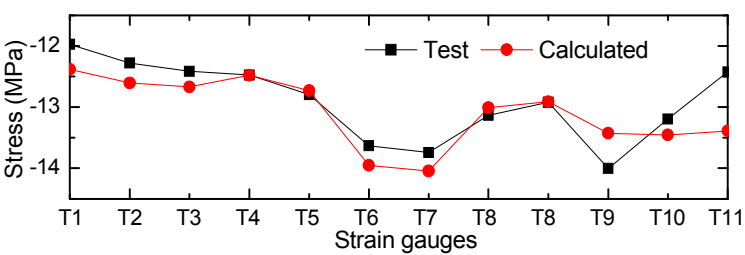

(a) Top plate, Case 1

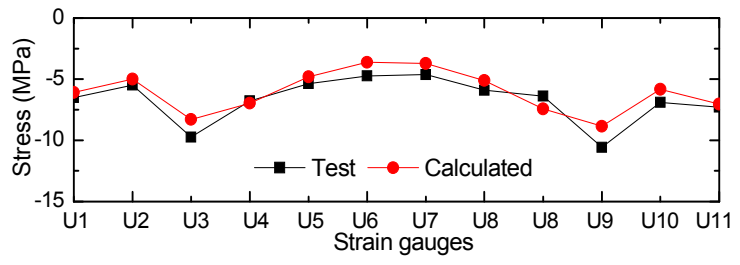

(c) U-rib, Case 1

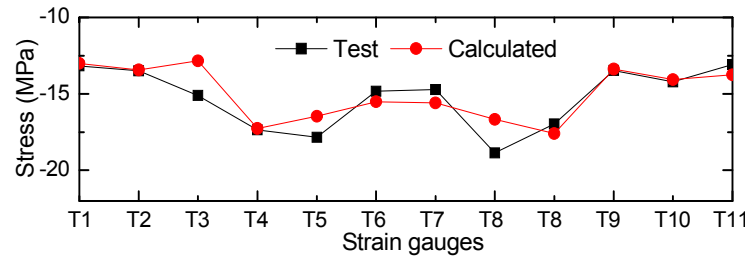

(b) Top plate, Case 2

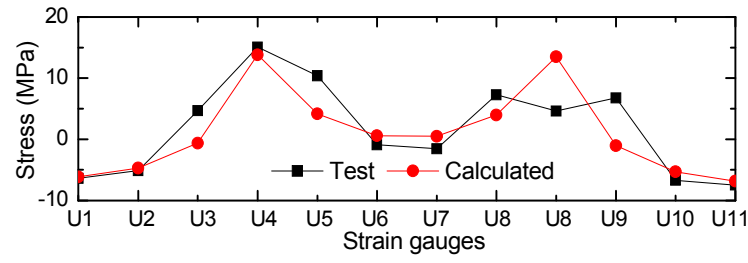

(d) U-rib, Case 2

Figure 5. Comparison between Calculated and Measured Stresses

\section{FATIGUE RELIABILITY ASSESSMENT USING PROBABLISITIC FE ANALYSIS}

\subsection{Fatigue Analysis Using AASHTO Approach}

The AASHTO approach to fatigue assessment is based on the S-N curves in the AASHTO design specification [6] and the Miner's rule. The AASHTO specification defines a number of S-N curves to account for the metallic fatigue life. Each curve is defined on the basis of nominal stress range vs life in cycles, and corresponds to one of the Category detail (A, B, C, etc.). The curves have a constant slope between $10^{5}$ and $10^{7}$ cycles, defined from experimental test data, and the curves are extended for longer lives using theoretical calculation, when $N$ is greater than $10^{7}$. The stress-life relationship is thus defined by:

$N=\frac{A \cdot \Delta}{S^{m}}$

where $N$ is the actual fatigue life in cycles of a detail; $A$ is the detail category constant; $\Delta$ is the Miner's critical damage accumulation index. $S$ is the constant stress range. When stress ranges are random variables, an equivalent stress range $S_{r e}$, which represents the same fatigue damage caused by a stress range histogram, should be used instead of $S$ :

$S_{r e}=\left[\sum \frac{n_{i}}{N} \cdot S_{i}^{m}\right]^{1 / m}$

where $m$ is the slope of S-N curves on log-log axes, and in most cases; $m$ has a value of 3.0. $n_{i}$ is the number of stress ranges corresponding to stress range $S_{i}$. 


\subsection{Fatigue Reliability}

The design of any structure requires that its resistance $R$ is greater than the load effect $S$. This requirement (i.e. $R>S$ ) is expressed as

$G(\boldsymbol{X})=R-S>0$

where $\boldsymbol{X}=\left\{\begin{array}{llll}X_{1} & X_{1} & , \cdots, X_{n}\end{array}\right\}^{T}$ denotes the vector of random variables; $G(\boldsymbol{X})=0$ represents the limit state.

In the context of fatigue assessment based on monitored data, according to Eq. (1), the limit state function in Eq. (3), can be written into

$G(\boldsymbol{X})=\Delta-e \cdot N \cdot\left(S_{r e}\right)^{m} / A=0$

where $e$ is an error factor of a typical measurement in SHM.

To consider the uncertainties that abound in the SHM as well as in the material resistance (S-N curves), parameters in Eq. (4) are treated as random variables. Frangopol et al. assumed that $e$ followed a lognormal distribution with the mean value of 1.0 and the COV of 0.3[22]. $A$ and $\Delta$ are also lognormally distributed variables. For Category details $\mathrm{B}$ and $\mathrm{E}$ in this study, the mean values of $A$ are $14.4 \times 10^{11}\left(\mathrm{MPa}^{3}\right)$ and $39.3 \times 10^{11}\left(\mathrm{MPa}^{3}\right)$ respectively and the COV is $0.45[21]$; the mean values of $\Delta$ is 1.0 and the $\mathrm{COV}$ is $0.3[25]$.

Assuming all the variables in Eq. (4) are independent, the fatigue reliability index $\beta$ can be written as [23]

$$
\beta=\frac{\sum \mu_{\ln X_{i, R}}-\sum \mu_{\ln X_{i}, S}}{\sqrt{\sum \sigma_{\ln X_{i}, R}^{2}+\sum \sigma_{\ln X_{i}, S}^{2}}}=\frac{\mu_{\ln \Delta}-\left\lfloor\mu_{\ln e}+\ln (N)-\mu_{\ln A}+m \cdot \mu_{\ln S_{r e}}\right\rfloor}{\sqrt{\ln \left[\left(1+\delta_{\Delta}^{2}\right) \cdot\left(1+\delta_{A}^{2}\right) \cdot\left(1+\delta_{e}^{2}\right)\right]+m^{2} \ln \left(1+\delta_{\ln S_{r e}}^{2}\right)}}
$$

where the accumulated number of cycles $N$ in the year $t$ can be estimated by the following equation:

$$
N(t)=365 \cdot A D T \cdot \int_{0}^{t}(1+\alpha)^{t} d t
$$

where $A D T$ represents the average daily vehicles and $\alpha$ is the traffic increase rate per year. Since $S_{r e}$ is obtained from the static FEA in which the dynamic amplification is not taken into account, a dynamic load amplification $(D L A)$, with a mean value of 1.10 and a standard deviation of 0.08 [26], is multiplied to the calculated $S_{r e}$. Considering that the variables in Eq. (5) should be lognormally distributed, the normal PDF of DLA is replaced by a lognormal PDF, which is the best fit of the normal PDF, with a mean value of 0.097 and a standard deviation of 0.073 . To this end, the limit state function in Eq. (4) can be established as

$G(\boldsymbol{X})=\Delta-e \cdot N(t) \cdot\left(D L A \cdot S_{r e}\right)^{m} / A=0$

Accordingly, Eq. (5) can be rewritten into

$$
\beta=\frac{\mu_{\ln \Delta}+\mu_{\ln A}-\left[\mu_{\ln e}+m \cdot \mu_{\ln S_{r e}}+m \cdot \mu_{\ln D L A}+\ln N(t)\right]}{\sqrt{\sigma_{\ln \Delta}^{2}+\sigma_{\ln A}^{2}+\sigma_{\ln e}^{2}+\left(m \cdot \sigma_{\ln D L A}\right)^{2}+\left(m \cdot \sigma_{\ln S_{r e}}\right)^{2}}}
$$




\subsection{Finite Element Analysis under Uncertainty}

To obtain the probabilistic distributions of $S_{r e}$, a probabilistic FEA code is developed in the MATLAB environment, and this probabilistic finite element analysis is performed according to the following procedure:

1) A uniformly distributed variable $V T$ is defined regarding the vehicle type, and $m$ numbers are generated in the value domain of $[0,1]$, which are used in $m$ times of finite element analyses to simulate $m$ vehicles crossing the bridge in a day (i.e., $m=1000$ ). In each FEA, the vehicle type is determined by the value of $V T(i),(i=1, \cdots, m)$, as shown in Table 1 . For instance, if $V T(i) \leqslant 0.7666$, loads of vehicle type 1 will be applied; if $0.7666<V T(i) \leqslant 0.7731$, loads of vehicle type 2 are applied, etc.

2) A uniformly distributed variable $N L$ is defined to determine the lane in which the vehicle travels. Similar to $V T, m$ numbers are generated in the value domain of $[0,1]$, and the value of $N L(i)$, $(i=1, \cdots, m)$, determines the transversal position of the vehicle loads. For instance, if loads of vehicle type 1 are to be applied and $N L(i)<0.0970$, loads should be applied in the outer lane; if $0.0970<N L(i) \leqslant 0.4123$, loads should be applied in the middle lane; otherwise, loads are in the inner lane.

3) A uniformly distributed variable $T$ is defined, and $m$ numbers are generated in the value domain of $[1,365]$. Previously, daily ambient temperatures are measured and form an uniform distribution with a volume of 365 . Therefore, the value of $T(i),(i=1, \cdots, m)$, determines the ambient temperature used in the FE analysis.

4) $m$ random numbers are generated for each variable in Table 1 (i.e., axle weights and axle spacing), according to normal or lognormal PDFs by using the truncated Latin Hypercube sampling (LHS) [27], and the correlations between axle weights and axle spacing are neglected to simplify the analysis.

5) According to the vehicle type, the transversal position of vehicle loads, axle loads and the axle spacing of the vehicle determined in the above three steps, loads of a vehicle are applied on the finite element model in ANSYS in $k$ load steps (i.e., $k=24)$. Each load step corresponds to a static FEA, and after each load step, the loads move forward to simulate the movement of the vehicle. Note that in each FE analysis, temperature loads are applied simultaneously and the corresponding changes are made to the elastic modulus of pavements, so that the influence of ambient temperatures on the fatigue stress spectra can be taken into account.

6) After each FEA, stresses at studied details under the moving loads are calculated, and the stress time-histories are obtained and output into a text file.

7) According to the simulated stress time-histories, rain-flow counting is made in the MATLAB environment to calculate $S_{r e}(i),(i=1, \cdots, m)$.

8) The probabilistic distributions of $S_{r e}$ are fitted according to $S_{r e}(i),(i=1, \cdots, m)$.

\subsection{Results and Discussion}

According to the above analysis procedure, fatigue reliability assessment is made for the RCB. First, the daily averaged temperature of the RCB in 2011 is obtained from the temperature gauge 
installed underneath the deck plates at the mid-span of the bridge, as shown in Figure 6, where seasonal fluctuations are clearly observed.

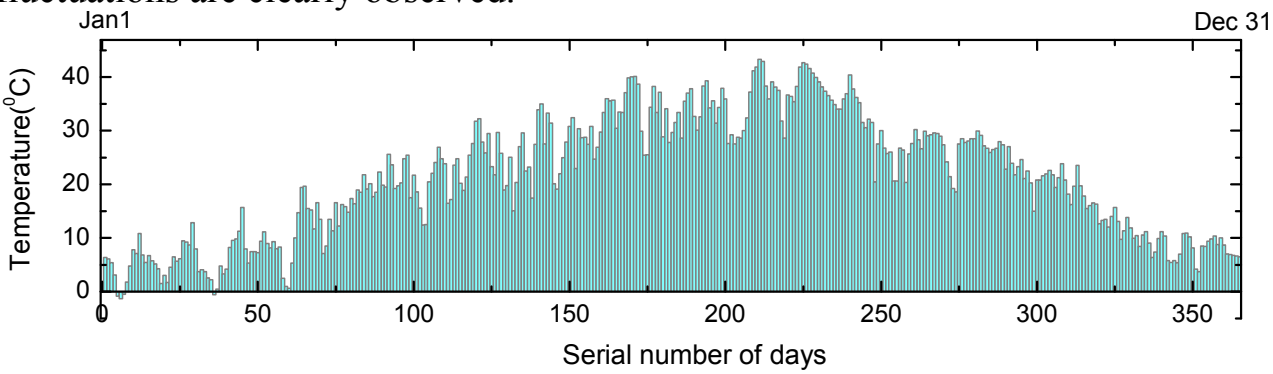

Figure 6. Daily Averaged Temperature from the SHM

Based on the procedure depicted in Section 4.2, probabilistic FE analyses are conducted, and three welded details in bridge decks are selected for evaluation, as shown in Figure 7. Weld $\mathrm{A}$ is the single-fillet weld at the rib-to-deck joint, whereas the Welds B and C are the butt welds at the U-rib and the top plate, respectively. According to the classification in AASHTO, Category detail C is assumed for Weld A and Category detail B is assumed for Welds B and C. In the following analyses, six positions on the bridge decks (i.e., Positions $1,2, \ldots, 6$ ) are selected for comparison, corresponding to the positions of stress gauges in Figure 4 (i.e., U1, U2,..., U6). For example, position A4, B4 and C4 represents the welds A, B and C near stress gauges U4, respectively.

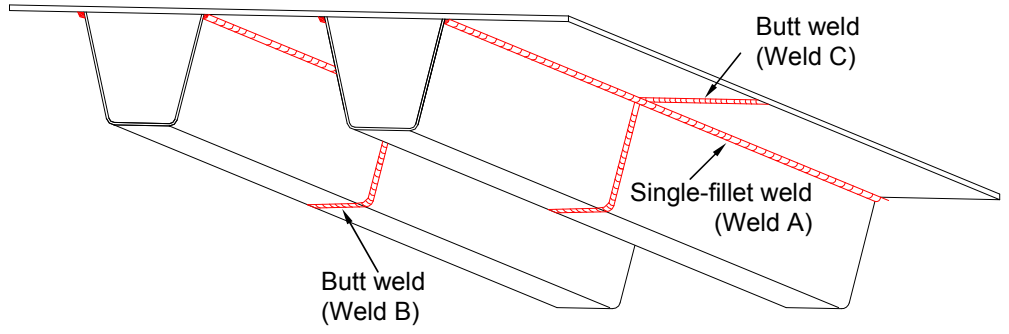

Figure 7. Welded Details in the OSD

Based on the FE analysis, Figure 8 shows stress time-histories of the three details under a moving truck (i.e., vehicle type 6) with mean axle weights as shown in Table 1. It is observed that welds A4 and $\mathrm{C} 4$ have similar responses while weld B4 shows a quite different pattern. Influence of six axles on stress time-histories can be clearly identified from the peaks or valleys of the stress time-histories.

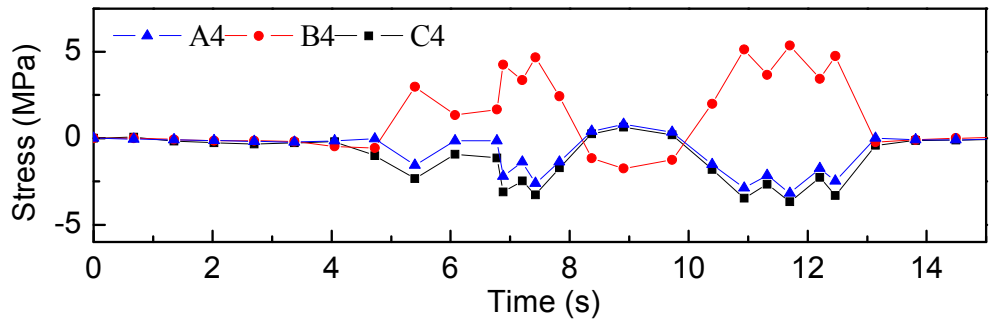

Figure 8. Stress Time-histories under A Moving Truck

According to the results of probabilistic analyses, PDFs of $S_{r e}$ of the three welded details are obtained, as shown in Figure 9, which in general can be described using lognormal PDFs. Taking A3 in Figure 9(a) for example, the mean value and the standard deviation of $\ln S_{\text {re }}$ are $8.125 \mathrm{MPa}$ and $2.844 \mathrm{MPa}$, while if the temperature effect is not considered, the values are $7.442 \mathrm{MPa}$ and 2.687MPa, respectively. Therefore, the temperature effect has a significant influence on the mean 
value of the $S_{r e}$. Based on the fitted PDFs of $S_{r e}$ and Eq. (8), fatigue reliabilities at each specific time can be calculated and to this end, time-variant reliabilities are obtained as shown in Figure 10. It is observed that the fatigue reliabilities decrease rapidly during the first ten to twenty years of service, and Weld A seems to have lowest reliabilities among the three details, though the mean values and standard deviations of $\ln S_{\text {re }}$ of the three welds are in general close to each other. Note that Weld A corresponds to the detail category $\mathrm{C}$ with a smaller value of the fatigue parameter $A$, as compared with Welds B and C. However, for the same welded detail (i.e., Weld A), the reliabilities at different positions are not the same, which is due to different $S_{r e}$ in these details and existence of longitudinal trusses. In general, details in outer lane with more heavy trucks and details in middle lane with highest vehicle occupation have lower reliabilities. Assuming the target reliability index $\beta_{\text {target }}$ is 1.5 , reliabilities of welds A may fall below $\beta_{\text {target }}$ prior to the designed life (i.e., 100 years).

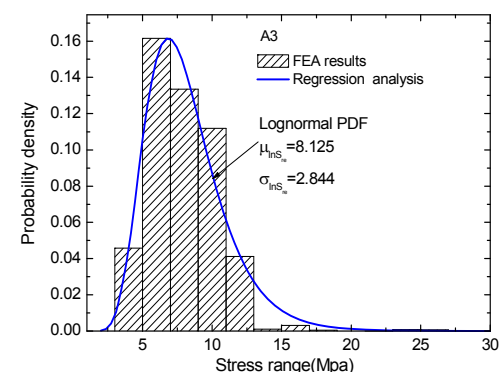

(a) A3

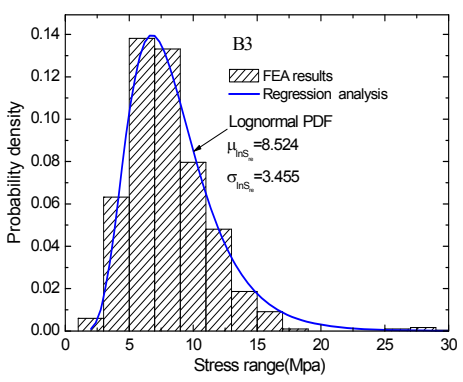

(b) B3

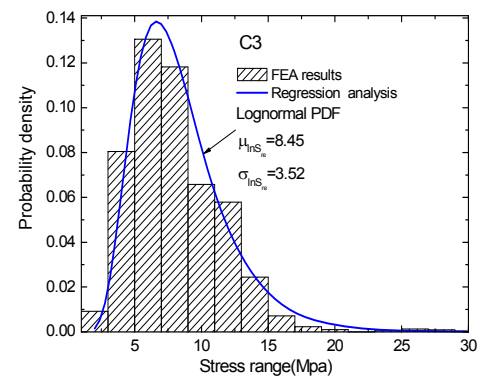

(c) $\mathrm{C} 3$

Figure 9. PDFs of $S_{r e}$ of Various Details

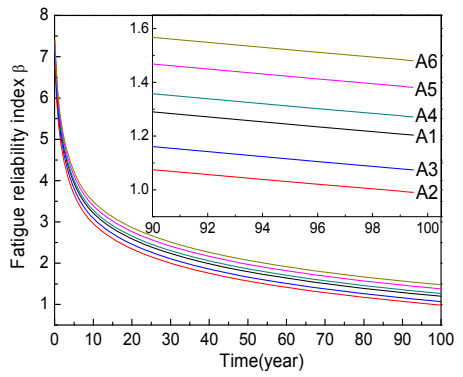

(a) Weld A

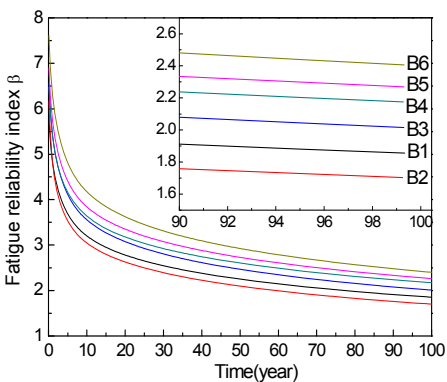

(b) Weld B

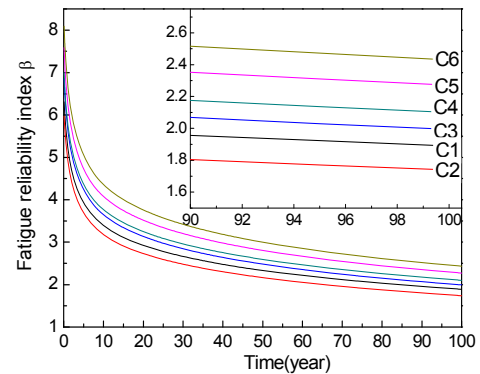

(c) Weld C

Figure 10. Time-variant Reliabilities of Various Details

\section{CONCLUSIONS}

This paper presents an approach to evaluate the time-variant reliabilities of the OSD of long-span bridges. Both measured vehicle loads and multi-scale finite element analysis are used in conjunction with the AASHTO fatigue evaluation methodology. Field measured responses are also adopted to calibrate the multi-scale FE model. The following conclusions can be drawn from this study.

(1) The proposed method provides a tool to evaluate the fatigue performance of the OSD with relatively lower costs and fewer limitations on the locations of details, as compared with the SHM. In addition, the coupling effect of vehicle loads and ambient temperature could be taken into account, which is the superiority over previous studies. The effectiveness of the proposed method, however, relies on the accuracy of the vehicle load models and the FE model of the bridge. 
(2) The multi-scale FE model enables an accurate description on the stresses in complex details; however, it is important to mesh the FE model in a most efficient way so that the computational cost is minimized.

(3) It is observed that fatigue reliabilities decrease rapidly during the first ten to twenty years of service, and Weld A seems to be the most vulnerable one among the three details. However, for the same welded detail (i.e., Weld A), the reliabilities at different positions are not the same. In general, details in middle lane and outer lane have relatively lower reliabilities.

(4) According to the presented analyses, reliabilities of some welded details may fall below $\beta$ target prior to the designed life. The future work of this ongoing study includes using monitored data and/or field inspection results to calibrate the proposed model.

\section{ACKNOWLEDGMENTS}

The financial support from 1) the Jiangsu Transportation Department under grants No. 2011Y09-2 and No. 2011Y03; 2) the Natural Science Foundation of Jiangsu under grants No. BK2011611 and No.BK20130023 and 3) the National Science Fund of China under grant No. 51178305 and the Key Projects in the Science \& Technology Pillar Program of Tianjin under grant No.11ZCKFSF00300 are gratefully acknowledged.

\section{REFERENCES}

[1] Partov, D. and Dinev, D., "Structure, Design and Construction of a Steel Orthotropic Bridge in Sofia ", Advanced Steel Construction, 2007, Vol. 3, No. 4, pp. 752-764.

[2] Jong, F.B.P.de. "Overview Fatigue Phenomenon in Orthotropic Bridge Decks in the Netherlands," 2004 Orthotropic Bridge Conference, Sacramento, California, USA, August 25-27, 2004.

[3] Wolchuk, R. "Lessons from Weld Cracks in Orthotropic Decks on Three European Bridges", Journal of Structural Engineering, 1990, Vol. 116, No.1, pp.75-84.

[4] Xiao, Z.G., Yamada, K., Inoue, J. and Yamaguchi, K. "Fatigue Cracks in Longitudinal Ribs of Steel Orthotropic Deck", International Journal of Fatigue, 2006, Vol.28, No.4, pp.409-416.

[5] Fisher, J.W., "Fatigue and Fracture in Steel Bridges", 1984, New York: John Wiley \& Sons.

[6] AASHTO. "Guide Specifications for Fatigue Evaluation of Existing Steel Bridges", Washington, DC: American Association of State Highway and Transportation Officials, 1990.

[7] BS5400. "Steel, Concrete and Composite Bridges, Part 10. Code of Practice for Fatigue", London: British Institute, 1982.

[8] Eurocode 3. "Design of Steel Structures - Part 1-9: Fatigue", London: British Institute, 2005.

[9] FHWA. "Manual for Design, Construction, and Maintenance of Orthotropic Steel Deck Bridges ( FHWA-IF-12-027)", February 2012.

[10] Kozy,B. M., Connor, R. J., Paterson,D. and Mertz,D. R. "Proposed Revisions to AASHTO-LRFD Bridge Design Specifications for Orthotropic Steel Deck Bridges", Journal of Bridge Engineering, 2011, Vol. 16, No. 6, pp.759-767.

[11] Guo, T., Li, A.Q. and Li, J.H. "Fatigue Life Prediction of Welded Joints in Orthotropic Steel Decks Considering Temperature Effect and Increasing Traffic Flow", Structural Health Monitoring-An International Journal, 2008, Vol. 7, No. 3, pp. 189-202. 
[12] Frýba, L., "Estimation of Fatigue Life of Railway Bridges Under Traffic Loads", Journal of Sound and Vibration, 2008, Vol. 70, No. 4, pp. 527-541.

[13] Szerszen, M.M., Nowak, A.S. and Laman, J.A., "Fatigue Reliability of Steel Bridges", Journal of Constructional Steel Research, 1999, Vol. 52, No. 1, 83-92.

[14] Freitas, S. T. D., Kolstein, H. and Bijlaard, F. "Structural Monitoring of a Strengthened Orthotropic Steel Bridge Deck Using Strain Data", Structural Health Monitoring, 2012, Vol.11, No.5, pp. 558-576.

[15] Li, Z.X., Chan, T.H.T. and Zheng, R., "Statistical Analysis of Online Strain Response and Its Application in Fatigue Assessment of a Long-span Steel Bridge", Engineering Structures, 2003, Vol. 25, No.14, pp.1731-1741.

[16] Leander, J., Anderson, A. and Karoumi, R. "Monitoring and Enhanced Fatigue Evaluation of a Steel Railway Bridge”, Engineering Structures, 2010,Vol. 32, No.3, pp .854-863.

[17] Wang, Y., Li, Z.X. and Li, A.Q. "Combined Use of SHMS and Finite Element Strain Data for Assessing the Fatigue Reliability Index of Girder Components in Long-span cable-stayed bridge", Theoretical and Applied Fracture Mechanics, 2010, Vol. 54, No. 3, pp.127-136.

[18] Zhou, Y.E. "Assessment of Bridge Remaining Fatigue Life Through Field Strain Measurement", Journal of Bridge Engineering, 2006, Vol. 11, No. 6, pp.737-744.

[19] Zhang, W. and Cai, C.S. "Fatigue Reliability Assessment for Existing Bridges Considering Vehicle Speed and Road Surface Conditions", 2012, Vol. 17, No. 3, pp. 443-453.

[20] Ni, Y.Q., Ye, X.W. and Ko, J.M. "Monitoring-based Fatigue Reliability Assessment of Steel Bridges: Analytical Model and Application", Journal of Structural Engineering, 2010, Vol.136, No.2, pp.1563-1573.

[21] Liu, M., Frangopol, D.M. and Kwon, K. "Fatigue Reliability Assessment of Retrofitted Steel Bridges Integrating Monitored data”, Structural Safety, 2010, Vol. 32, No.1, pp.77-89.

[22] Frangopol, D. M., Strauss, A. and Kim, S., "Bridge Reliability Assessment Based on Monitoring", Journal of Bridge Engineering, 2008, Vol. 13, No. 3, pp. 258-70.

[23] Guo, T., Frangopol, D.M. and Chen, Y.W., "Fatigue Reliability Assessment of Steel Bridge Details Integrating Weigh-in-motion Data and Probabilistic Finite Element Analysis", Computers \& Structures, 2012, Vol. 112-113, pp. 245-257.

[24] Ni, Y.Q., Ye, X.W. and Ko, J.M., "Modeling of Stress Spectrum Using Long-term Monitoring Data and Finite Mixture Distributions", Journal of Engineering Mechanics (ASCE), 2012, Vol.138, No.2, 175-183.

[25] Wirsching, P. H. "Fatigue Reliability for Offshore Structures", Journal of Structural Engineering, 1984, Vol. 110, No.10, pp. 2340-2356.

[26] Kulicki, J.M., Prucz, A., Clancy, C.M., Mertz, D.R. and Nowak, A.S., , "Updating the Calibration Report for AASHTO LRFD code", NCHRP 20-07/186, Transportation Research Board, National Research Council, Washington, DC, 2007.

[27] Stein, M., "Large Sample Properties of Simulations Using Latin Hypercube Sampling", Technometrics. 1987, Vol. 29, No. 2, pp. 143-151. 